\title{
Association of vitamin D status with risk factors for metabolic syndrome in overweight young adults
}

\author{
S. Muldowney ${ }^{1}$, A. Lucey ${ }^{1}$, G. Paschos $^{1}$, J. A. Martinéz ${ }^{2}$, I. Thorsdottir ${ }^{3}$, K. D. Cashman ${ }^{1,4}$ \\ and M. Kiely ${ }^{1}$ \\ ${ }^{1}$ Departments of Food \& Nutritional Sciences and ${ }^{4}$ Medicine, University College Cork, Cork, Republic of Ireland, \\ ${ }^{2}$ Department of Physiology \& Nutrition, University of Navarra, Spain and ${ }^{3}$ Unit for Nutrition Research, \\ Landspitali University Hospital, Iceland
}

Low vitamin D status may be associated with increased risk of metabolic syndrome (MetS $)^{(1,2)}$. The objective was to explore associations between vitamin D status and MetS risk factors in young overweight European adults. The present report is a post-hoc analysis of baseline data obtained from 197 adults (age 20-40 years, BMI range 27.5-32.5 kg/m ${ }^{2}$ ) who participated in the Seafoodplus 'Young' weight-loss intervention study. Anthropometric measurements, blood pressure (BP) and fasting blood samples were collected during late winter, when vitamin D status is at its nadir ${ }^{(3)}$. Serum 25-hydroxyvitamin D (25(OH)D), total cholesterol, HDL- and LDL-cholesterol, TAG, glucose, insulin, high-sensitivity C-reactive protein (hsCRP), intracellular and vascular cell adhesion molecules (ICAM and VCAM) and plasminogen activator inhibitor type 1 (PAI-1) were analysed in eighty-six men and 111 women from Iceland ( $n$ 82), Ireland ( $n$ 39) and Spain $(n$ 76). Statistical analysis was performed in SPSS V15 (SPSS Inc., Chicago, IL, USA), using analysis of covariance and multiple linear regression analysis, controlling for age, gender and country.

Serum 25(OH)D concentration $(\mathrm{nmol} / \mathrm{l})$ was 56.2 (SD 24.0) for the group, with significant differences $(P<0.0001)$ between the three countries: Iceland 44.8 (SD 17.3), Spain 69.3 (SD 26.1) and Ireland 54.6 (SD 19.7). Approximately half the subjects had serum 25(OH)D levels $<50 \mathrm{nmol} / \mathrm{l}$, which is an internationally-recognised threshold of insufficient vitamin D status. The prevalence of MetS (defined by meeting three or more of the American Heart Association/National Heart Lung and Blood Institute (AHA/NHLBI) ${ }^{(4)}$ criteria was $17 \%$. Subjects who had less than three MetS criteria had significantly higher $(P=0.046) 25(\mathrm{OH}) \mathrm{D}$ levels $(57.4$ (SD 24.8$) \mathrm{nmol} / \mathrm{l})$ than those who had MetS (49.8 (SD 19.7) nmol/l) after controlling for age, gender and country. The Table compares the AHA/NHLBI diagnostic criteria for MetS across tertiles $(\mathrm{T})$ of $25(\mathrm{OH}) \mathrm{D}$ status (nmol/1; T1, $\leq 43.00 ; \mathrm{T} 2,43.01-63.50 ; \mathrm{T} 3, \geq 63.50)$.

\begin{tabular}{|c|c|c|c|c|c|c|c|}
\hline \multirow[b]{3}{*}{ MetS criteria (AHA/NHLBI) } & \multicolumn{6}{|c|}{ Tertiles of serum $25(\mathrm{OH}) \mathrm{D}$} & \multirow[b]{3}{*}{$P$} \\
\hline & \multicolumn{2}{|c|}{$\mathrm{T} 1(n 66)$} & \multicolumn{2}{|c|}{$\mathrm{T} 2(n 66)$} & \multicolumn{2}{|c|}{ T3 $(n 65)$} & \\
\hline & Mean & SD & Mean & $\mathrm{SD}$ & Mean & SD & \\
\hline Waist circumference $(\mathrm{cm})$ & 96.1 & 7 & 95.8 & 7 & 95.6 & 8 & 0.539 \\
\hline Systolic BP (mmHg) & 128 & 10 & 125 & 13 & 126 & 12 & 0.557 \\
\hline Diastolic BP $(\mathrm{mmHg})$ & $74.5^{\mathrm{a}}$ & 7 & $71.2^{\mathrm{b}}$ & 8 & $72.1^{\mathrm{ab}}$ & 7 & 0.034 \\
\hline HDL-cholesterol $(\mathrm{mmol} / \mathrm{l})$ & 1.3 & 0.36 & 1.33 & 0.31 & 1.43 & 0.38 & 0.058 \\
\hline TAG $(\mathrm{mmol} / \mathrm{l})$ & $1.33^{\mathrm{a}}$ & 0.63 & $1.11^{\mathrm{b}}$ & 0.66 & $1.13^{\mathrm{b}}$ & 0.67 & 0.009 \\
\hline Fasting glucose $(\mathrm{mmol} / \mathrm{l})$ & 4.89 & 0.38 & 4.97 & 0.44 & 5.03 & 0.55 & 0.988 \\
\hline
\end{tabular}

${ }^{\mathrm{a}, \mathrm{b}}$ Values with unlike superscript letters were significantly different.

Diastolic BP $(P=0.034)$ and serum TAG were significantly higher $(P=0.009)$ in subjects in the lowest tertile $(\mathrm{T} 1)$ of $25(\mathrm{OH}) \mathrm{D}$ compared with T2 and T3. However, serum 25(OH)D concentration was not a significant predictor of any of the MetS risk factors. In conclusion, these data show a weak association between MetS risk factors and vitamin D status in young overweight adults, which should be investigated using controlled intervention studies.

The YOUNG study (coordinator Professor Inga Thorsdottir) is part of the SEAFOODplus Integrated Project, which is funded by the EC through the 6th Framework Programme contract no. FOOD-CT-2004-506359.

1. Chiu KC, Chu A, Go VLW et al. (2004) Am J Clin Nutr 79, 820-825.

2. Ford ES, Ajani UA, McGuire LC et al. (2006) Diabetes Care 28, 1228-1230.

3. van der Wielen RP, Lowik MR, van den Berg H et al. (1995) Lancet 346(8969), 207-210.

4. Grundy SM, Cleeman JI, Daniels SR et al. (2005) Cardiol Rev 13(6), 322-327. 